\title{
PENGARUH KEMAMPUAN KERJA, MOTIVASI KERJA, LINGKUNGAN KERJA DAN BUDAYA ORGANISASI TERHADAP KINERJA PEGAWAI DINAS PENDIDIKAN KABUPATEN BARITO SELATAN
}

\author{
Nilawati \\ Sekolah Tinggi Ilmu Ekonomi Pancasetia Banjarmasin \\ Jl. Ahmad Yani Km. 5.5 Banjarmasin \\ nil4marhan@gmail.com
}

This research is to analyze the influence, motivation, opportunities, and partial participation on employee performance in the Dinas Pendidikan Kabupaten Barito Selatan. The object of research was employees at the Dinas Pendidikan Kabupaten Barito Selatan. A total of 500 employees. Determination of the sample in this study using simple random sampling, with a sample of $10 \%$ of the total sample used for as many as 50 respondents. The independent variables in this study are ability, motivation, opportunity, and discipline, while the required variable is employee work performance. The analysis technique used is multiple linear regression analysis.

Transformed regression shows all regression coefficients that are positive, which means all expected independent variables in the model have a direction of change in the direction of the added variables, meaning that the independent variable rises assuming the other independent variables remain free so that the variable rises as well. Based on the analysis results it is concluded that the independent variables collected have a significant effect on the dependent variable. This can be assessed from the results of the $t$ statistical calculation, the $t$ value is greater than $t$ table. The results showed that:

1. Ability (X1) influences employee performance (Y) with a t value of 5.313 greater than $t$ table of 1.701 with a significance level of 0,000 .

2. Motivation (X2) affects employee performance (Y) with a t value of 2.780 greater than $t$ table of 1.701 with a significance level of 0.007 .

3. Opportunity (X3) influences employee performance (Y) with a t value of 2.116 greater than $\mathrm{t}$ table of 1.701 with a significant degree of 0.038 .

4. Discipline (X4) has an effect on employee performance (Y) with a t value of 3.922 greater than $t$ table of 1.701 with a significant degree of 0,000 .

5. The conversion coefficient is Multiple $\mathrm{R}$ of 0.512 , this shows that there is a strong relationship between independent variables consisting of ability (X1), motivation (X2), opportunity (X3), and discipline (X4) together to support the achievement employment at Dinas Pendidikan Kabupaten Barito Selatan. This relationship is categorized as strong because of the value

Keyword: Employee's Ability, Motivation, Opportunity, Discipline, and Work Performance. 


\section{PENDAHULUAN}

\subsection{Latar Belakang Masalah}

Kantor Dinas Pendidikan Kabupaten Barito Selatan memiliki sistim pengelolaan sumber daya manusia yang sepenuhnya belum sempurna seperti halnya perusahaan yang modern meskipun telah menggunakan sistem jaringan dengan memanfaatkan software tetapi para pegawai tetap merupakan kunci keberhasilan pelayanan kepada masyarakat yang menjadi tanggungjawabnya, karena sumber daya manusia tidak saja dipandang sebagai unsur produksi tetapi juga sebagai manusia yang memiliki emosi dan keunikan tersendiri serta kepribadian yang berbeda dengan sumber daya lainnya karena dia juga perlu kompensasi, promosi gaji dan reward. Menurut teori harapan Vroom yang menyatakan bahwa setiap orang memiliki kombinasi instrumen nilai dan harapan yang unik. Kemampuan yang tinggi dari individu tanpa adanya motivasi atau dorongan untuk bertindak, dan tidak memiliki sikap mental baik, tidak akan dicapai prestasi kerja yang tinggi demikian sebaliknya, bahwa dengan motivasi yang tinggi tanpa ditunjang sikap mental yang kokoh dan kemampuan untuk melaksanakan pekerjaan, maka tidak akan dicapai pula prestasi kerja yang tinggi. Kemampuan kerja dapat dilihat dari intrapersonal skill, interpersonal skill, professional skill, problem solving skill dan learning skill. Motivasi merupakan kondisi yang mendorong atau menggerakkan karyawan agar mampu mencapai tujuan. Tiap karyawan mempunyai motivasi atau dorongan yang berbeda-beda agar mau bekerja dengan baik. Tingginya motivasi kerja serta kebanggaan menjadi bagian dari perusahaan atau organisasi dapat menjadi kekuatan besar bagi karyawan bersangkutan untuk berusaha mempertahankan keanggotaannya dengan perusahaan tersebut. Menurut Gardner (1983) dalam Ubaedy (2008), faktor-faktor yang mempengaruhi dalam usaha membangun kemampuan tinggi seseorang terdiri dari; intrapersonal skill, interpersonal skill, professional skill, problem solving dan learning skill. Kemampuan akan mendorong terbentuknya sikap diri dalam bekerja dan memandang lingkungannya lebih positif serta cenderung akan memiliki komitmen yang tinggi terhadap organisasi. Dalam suatu organisasi pemerintahan seperti pada Kantor Dinas Pendidikan Kabupaten Barito Selatan unsur kemampuan kerja atau kompetensi, motivasi diri para pegawai sangat berbeda dan variatif kualitas ataupun tujuannya pribadinya. Selain kemampuan kerja dan motivasi, faktor lain yang mempengaruhi kinerja pegawai adalah budaya organisasi, karena budaya organisasi memiliki dampak pada efisien dan efktivitas organisasi. Lingkungan kerja dikatakan mendukung karena tanpa lingkungan kerja yang memadai, maka pekerjaan akan terhambat, terganggu bahkan dapat terhenti sama sekali. Artinya kinerja organisasi ataupun kinerja anggota akan sangat rendah jika anggota dalam melaksanakan tugasnya tidak didukung oleh lingkungan kerja yang kondusif.

Berdasarkan hal-hal tersebut maka perlu diteliti suatu kajian tentang variabelvariabel yang mempengaruhi kinerja pegawai pada Kantor Dinas Pendidikan Kabupaten Barito Selatan yang meliputi variabel budaya organisasi, lingkungan kerja, motivasi dan kompetensi atau kemampuan kerja. 


\subsection{Rumusan Masalah}

Dengan mengacu pada uraian yang telah dijelaskan pada latar belakang maka peneliti ingin mengetahui :

1. Apakah variabel Kemampuan Kerja , Motivasi Kerja, Lingkungan Kerja dan Budaya Organisasi, berpengaruh secara simultan terhadap Kinerja Pegawai pada Kantor Dinas Pendidikan Kabupaten Barito Selatan?

2. Apakah variabel Kemampuan Kerja, Motivasi Kerja, Lingkungan Kerja dan Budaya Organisasi, berpengaruh secara parsial terhadap Kinerja Pegawai pada Kantor Dinas Pendidikan Kabupaten Barito Selatan?

3. Variabel manakah yang dominan mempengaruhi Kinerja Pegawai pada Kantor Dinas Pendidikan Kabupaten Barito Selatan?

\subsection{Tujuan Penelitian}

1. Untuk mengetahui dan menganalisis pengaruh Kemampuan Kerja, Motivasi Kerja, Lingkungan Kerja dan Budaya Organisasi, secara simultan terhadap Kinerja Pegawai pada Kantor Dinas Pendidikan Kabupaten Barito Selatan.

2. Untuk mengetahui dan menganalsis pengaruh pengaruh Kemampuan Kerja, Motivasi Kerja, Lingkungan Kerja dan Budaya Organisasi, secara parsial terhadap Kinerja Pegawai pada Kantor Dinas Pendidikan Kabupaten Barito Selatan.

3. Untuk mengetahui dan menganalisis pengaruh yang dominan diantara variabel Kemampuan Kerja, Motivasi Kerja, Lingkungan Kerja dan Budaya Organisasi, terhadap Kinerja Pegawai pada Kantor Dinas Pendidikan Kabupaten Barito Selatan.

\subsection{Landasan Teori}

\subsubsection{Kemampuan Kerja}

Sumber daya manusia adalah unsur yang penting dalam organisasi, hal ini dikarenakan unsur-unsur yang lain seperti modal / uang, bahan baku, metode dalam bekerja dan sumber daya lainnya hanya dapat memberi manfaat bagi organisasi, jika sumber daya manusia yang ada di dalam organisasi tersebut mampu merekayasa dalam menghasilkan suatu karya yang bermanfaat bagi kelangsungan hidup organisasi atau untuk mencapai tujuan organisasi. Dengan kata lain, bahwa manusia adalah faktor pengendali dan perangsang ke arah tercapainya tujuan organisasi dengan tingkat efektifitas dan efisiensi tertentu. Dengan demikian, manusia merupakan modal yang sangat berharga bagi segala aktifitas yang dilakukan organisasi (Robbins 2001: 37).

Hersey dan Blanchard (1995: 187) mengatakan bahwa pendidikan dan atau pengalaman mempengaruhi kemampuan dan motivasi berprestasi. Pendidikan dan pengalaman tidak ada perbedaan konseptual diantara keduanya. Hanya bila berbicara tentang pendidikan, mengacu pada pengalaman pendidikan formal dan pengalaman merupakan hal-hal yang dipelajari seseorang atau yang diperoleh dari pekerjaan.

\subsubsection{Faktor-Faktor Mempengaruhi Kerja \\ yang \\ Kemampuan}

Karyawan operasional dalam organisasi apapun harus meningkatkan kualitas kemampuannya dan dituntut agar dapat bekerja cheaper, better, faster and smarter, sehingga pihak yang berhubungan dengan organisasi merasa puas dilayani. Salah satu kebijakan yang dapat diambil adalah dengan membangun kemampuan tinggi dari sikap karyawan dengan meningkatkan kemampuan 
teknis, teoritis, konseptual dan moral karyawan sesuai dengan kebutuhan pekerjaan/jabatan.

Menurut Gardner (1983) dalam Ubaedy (2008), indikator yang membangun kemampuan tinggi seseorang terdiri dari; intrapersonal skill, interpersonal skill, professional skill, problem solving dan learning skill.

\subsubsection{Motivasi Kerja}

Stoner (2006 : 32) mengatakan motivasi adalah dorongan dari dalam maupun dari luar yang ada pada diri seseorang. Orang akan termotivasi untuk melakukan suatu pekerjaan untuk mencapai sasaran yang dianggapnya lebih berharga, dengan demikian ia akan bekerja sekuat tenaga yang dimilikinya demi tercapainya tujuan yang diinginkan. Selanjutnya menurut Siagian (2006 : 31), motivasi adalah daya pendorong yang mengakibatkan seseorang anggota organisassi mau dan rela untuk menggerakkan kemampuan dalam bentuk keahlian atau ketrampilan, tenaga dan waktunya untuk menyelenggarakan berbagai kegiatan yang menjadi tanggung jawabnya dan memfungsikan kewajibannya dalam rangka mencapai tujuan organisasi yang telah ditentukan sebelumnya.

Menurut Gomes (2007 : 48), Motivasi seorang karyawan untuk bekerja biasanya ditunjukkan oleh aktivitas yang terus menerus yang berorientasikan tujuan karyawan yang bermotivasi adalah mereka yang prilakunya diarahkan kepada tujuan organisasi dan aktivitasaktivitasnya tidak mudah terganggu oleh gangguan kecil demikian sebaliknya. Motivasi pada dasarnya adalah proses untuk mencoba mempengaruhi seseorang agar melakukan sesuatu yang kita nginkan, dengan kata lain merupakan dorongan dari luar terhadap seseorang agar melakukan sesuatu. Motivasi sebagai pekerjaan yang dilakukan seorang manajer dalam memberikan inspirasi, semangat dan dorongan kepada orang lain, untuk mengambil tindakantindakan pemberian dorongan ini bertujuan untuk menggiatkan orangorang atau karyawan agar mereka bersemangat dan mencapai hasi sebagaimana dikehendaki dari orangorang tersebut.

Menurut Nimran (2007 : 32), bahwa pada dasarnya ada tiga karakteristik pokok dari motivasi yaitu : usaha, kemauan yang kuat dan arah tujuan. Ketiga karakteristik pokok motivasi ini dapat didefinisikan sebagai keadaan dimana usaha dan kemauan seseorang diarahkan kepada pencapaian hasil-hasil tertentu. Hasil-hasil yang dimaksud berupa produktivitas kehadiran atau perilaku kerja.

Menurut Kontz (2006 : 72) mengatakan bahwa motivasi rantai reaksi yang diawali dengan adanya kebutuhan yang selanjutnya menimbulkan tensi (ketegangan) yaitu keinginan yang belum terpenuhi yang kemudian menyebabkan timbulnya tindakan untuk mengarahkan tujuan dan akhirnya memuaskan keinginan. Kebutuhan-kebutuhan yang dimaksud bukanlah kebutuhan yang sederhana, karena kebutuhan itu sendiri dapat pula menimbulkan keinginan untuk memuaskan kebutuhan yang lain.

Berdasarkan definisi yang diutarakan di atas dapat diketahui bahwa Motivasi kerja adalah dorongan dan kemauan yang mendorong seorang anggota organisasi mau dan rela untuk menggerakkan kemampuan untuk melakukan kegiatan agar tercapai tujuan organisasi

\subsubsection{Lingkungan Kerja}

Lingkungan kerja adalah tempat di mana pegawai melakukan aktivitas setiap harinya. Lingkungan kerja yang kondusif 
memberikan rasa aman dan memungkinkan pegawai untuk dapat bekerja optimal. Lingkungan kerja dapat mempengaruhi emosi pegawai. Jika pegawai menyenangi lingkungan kerja di mana dia bekerja, maka pegawai tersebut akan betah di tempat kerjanya, melakukan aktivitas sehingga waktu kerja dipergunakan secara efektif. Produktivitas akan tinggi dan optimis prestasi kerja pegawai juga tinggi. Lingkungan kerja itu mencakup hubungan kerja yang terbentuk antara sesama pegawai dan hubungan kerja antar bawahan dan atasan serta lingkungan fisik tempat pegawai bekerja. Menurut Nitisemito (2004 : 200) mendefenisikan lingkungan kerja sebagai berikut : "Lingkungan kerja adalah sesuatu yang ada di sekitar para pekerja yang dapat mempengaruhi dirinya dalam menjalankan tugas-tugas yang diembankan". Menurut Sedarmayati (2004 : 89) mendefenisikan lingkungan kerja sebagai berikut : "Lingkungan kerja adalah keseluruhan alat perkakas dan bahan yang dihadapi, lingkungan sekitarnya di mana seseorang bekerja, metode kerjanya, serta pengaturan kerjanya baik sebagai perseorangan maupun sebagai kelompok". Lebih lanjut Gitosudarmo dalam Sujadi (2007 : 19), menyatakan bahwa lingkungan kerja terdiri dari lingkungan fisik dan lingkungan organisasi yang menjadikan iklim kerja positif. Hal senada juga dinyatakan oleh Kaho dalam Sujadi (2007 : 19), bahwa dalam persiapan otonomi daerah perlu didukung oleh lingkungan kerja yang kondusuf berupa ketersediaan sumber daya non manusia seperti; kendaraan, gedung, peralatan, materi dan lain-lain. Hal yang sama juga dikatakan Sutermeister dalam Sujadi (2007 : 19), bahwa indikator lingkungan kerja merupakan physical condition yang meliputi lighting, temperature, ventillation, rest period, safety, dan suasana kerja.

Dari beberapa pendapat diatas dapat disimpulkan bahwa lingkungan kerja adalah segala sesuatu yang ada di sekitar para pekerja, yang keberadaannya penting untuk membangkitkan semangat dan gairah kerja karyawan dalam menjalankan tugas sehari-hari, terutama dalam menunjang tingkat kinerja karyawan. Dan lingkungan kerja merupakan segala sesuatu yang ada di sekitar karyawan pada saat bekerja, baik yang berbentuk fisik ataupun non fisik, langsung atau tidak langsung, yang dapat mempengaruhi dirinya dan pekerjaanya saat bekerja.

\subsubsection{Budaya Organisasi}

Menurut Robbins (2002 : 280) menyatakan bahwa "Budaya organisasi adalalah seperangkat nilai, kepercayaan dan pemahaman yang penting sama-sama dimiliki oleh para anggotanya". Ia menyatakan nilai-nilai atau ide-ide kepercayaan bahwa yang sama-sama dianut oleh para anggota itu seperti terwujud dalam alat-alat simbolis seperti mitos, upacara, cerita, legenda dan bahasa khusus. Budaya organisasi tercermin pada pola pikir, berbicara dan perilaku yang konsisten pada anggota atau pegawai yang terlibat dalam pengelolaan organisasi, misalnya menyangkut cara mengambil keputusan, cara berkomunikasi, dan cara berinteraksi di dalam lingkungan internal dan lingkungan eksternal organisasi. Perilaku kerja dan hubungan kerja yang berada dalam organisasi semuanya berpedoman pada budaya organisasi yang telah menjadi pedoman kerja. 


\subsubsection{Kinerja}

Kata kinerja berasal dari bahasa Inggris "performance" yaitu prestasi. Dengan demikian kinerja pegawai diartikan sebagai prestasi yang dicapai seorang Pegawai dalam melaksanakan tugas yang dipercayakan kepadanya. Menurut Mulyasa (2004 : 11), kinerja atau performansi diartikan sebagai prestasi kerja, pelaksanaan kerja, hasil kerja atau unjuk kerja. Lebih lanjut Fatah (2006 : 16), mengatakan kinerja merupakan ungkapan kemajuan yang didasari oleh pengetahuan, sikap, ketrampilan dan motivasi dalam menghasilkan sesuatu.

Hasibuan (2004 : 8), mengatakan bahwa kinerja adalah suatu hasil kerja yang dicapai seseorang dalam melaksanakan tugas-tugas yang dibebankan kepadanya yang didasarkan atas kecakapan, pengalaman dan kesungguhan serta waktu. Lebih lanjut Hasibuan (2004 : 12), mengatakan bahwa kinerja Pegawai merupakan gabungan 3 faktor penting yaitu ; kemampuan, perangai dan minat seorang Pegawai; kejelasan dan penerimaan atas penjelasan peranan seorang Pegawai dan tingkat motivasi kerja. Kemudian dengan singkat Mathis and Jackson (2004 : 76) mengatakan bahwa kinerja adalah kualitas dan kuantitas hasil kerja yang ditunjukkan oleh Pegawai tersebut.

Sementara As'ad (2005 : 12), mendefinisikan "Kinerja sebagai hasil yang dicapai oleh seseorang menurut ukuran yang berlaku untuk suatu pekerjaan yang bersangkutan". Sedangkan Mitchell dan Larson (2005 : 23) mengatakan bahwa "Kinerja menunjukan pada suatu hasil perilaku yang dinilai oleh beberapa kriteria atau standar mutu suatu hasil kerja. Persoalan mutu ini berkaitan dengan baik buruknya hasil yang dikerjakan oleh pegawai. Bila perilaku pegawai memberikan hasil pekerjaan yang sesuai dengan standart atau kriteria yang ditetapkan organisasi, maka prestasi kerjanya tergolong baik. Sebaliknya bila perilaku pegawai memberikan hasil pekerjaaan yang kurang atau tidak sesuai dengan standar atau kriteria yang ditetapkan oleh organisasi, maka kinerjanya tergolong kurang baik". Berdasarkan beberapa pengertian di atas, dapat diketahui bahwa kinerja Pegawai adalah hasil yang dicapai oleh pegawai dalam melaksanakan proses pekerjaan yang digunakan sebagai dasar penilaian atas diri Pegawai atau organisasi kerja yang bersangkutan.

\section{HIPOTESIS}

Berdasarkan kerangka dasar teori yang telah dijelaskan diatas, maka dalam kaitannya dengan penelitian ini dengan judul yang diajukan tentang Pengaruh Kemampuan Kerja, Motivasi Kerja, Lingkungan kerja, dan Budaya Organisasi Terhadap Kinerja Pegawai Kantor Dinas Pendidikan Kabupaten Barito Selatan, maka diajukan hipotesis sebagai berikut :

1. Variabel Kemampuan Kerja, Motivasi Kerja, Lingkungan Kerja dan Budaya Organisasi, secara simultan terhadap Kinerja Pegawai pada Kantor Dinas Pendidikan Kabupaten Barito Selatan.

2. Variabel Kemampuan Kerja, Motivasi Kerja, Lingkungan Kerja dan Budaya Organisasi, secara parsial terhadap Kinerja Pegawai pada Kantor Dinas Pendidikan Kabupaten Barito Selatan.

3. Variabel Lingkungan Kerja mempunyai pengaruh secara dominan terhadap Kinerja Pegawai pada Kantor Dinas Pendidikan Kabupaten Barito Selatan.

\section{METODE PENELITIAN}

Penelitian ini bersifat explanatory terhadap variabel yang diteliti yaitu variabel-variabel yang akan dianalisis adalah variabel 
tergantung atau dependent variable (Y) yang terdiri satu variabel yaitu kinerja pegawai pada Kantor Dinas Pendidikan Kabupaten Barito Selatan, sedangkan variabel bebas atau independent variable $(\mathrm{X})$ terdiri dari $\mathrm{X}_{1}=$ Kemampuan kerja, $\mathrm{X} 2=$ Motivasi, $\mathrm{X} 3$ = Lingkungan Kerja, X4 = Budaya Organisasi.

\subsubsection{Jenis Data}

Dalam penelitian ini jenis data yang dibutuhkan adalah :

1. Data kuantitatif, yaitu data yang berupa angka-angka dan disajikan dalam bentuk tabel atas perhitunganperhitungan matematis maupun statistik.

2. Data kualitatif, yaitu data yang sifatnya berupa informasi yang didasarkan pada pendekatan teoritis dan pemikiran yang logis.

\subsubsection{Sumber Data}

Dalam penelitian ini sumber data yang dibutuhkan berasal dari :

a. Data primer yaitu data yang diperoleh langsung dari hasil penyebaran kuesioner yang dilakukan peneliti kepada para pegawai tetap atau pegawai negeri sipil dan pegawai honorer..

b. Data sekunder yaitu data yang diperoleh dalam bentuk sudah diolah, seperti dokumen instansi, buku literatur, jurnal dan sumber data lainnya

\subsection{Populasi dan Sampel}

Populasi dalam penelitian ini adalah pegawai tetap atau PNS, pegawai honorer, yang seluruhnya berjumlah 58 responden dengan menggunakan sampel jenuh atau sensus, yaitu semua populasi menjadi sampel penelitian (Sugiyono, 2006 : 78).

\subsection{Teknik Pengumpulan Data}

Teknik pengumpulan data data dalam penelitian ini dilakukan dengan menggunakan beberapa cara berikut : a. Survey lapangan yaitu berupa kegiatan observasi dan wawancara langsung dengan pihak-pihak yang terkait dalam instansi untuk memperoleh data dan informasi-informasi yang diperlukan.

b. Melalui kuisioner yang disebarkan oleh peneliti dan jawaban dari kuisioner dikompilasi sebagai dasar untuk menganalisis hasil penelitian.

c. Studi kepustakaan yaitu berupa kegiatan mengumpulkan dan mempelajari data jadi yang diperoleh dari instansi disesuaikan dengan teori-teori yang mendukung.

d. Observasi, data yang diambil melalui informasi dari internet dan media massa.

\section{ANALISIS HASIL PENELITIAN DAN PEMBAHASAN}

1. Karakteristik Responden berdasarkan Usia.

\begin{tabular}{|c|c|c|c|}
\hline KELAS & $\begin{array}{c}\text { INTERVAL } \\
\text { KELAS }\end{array}$ & FREKUENSI & PROSENTASE \\
\hline$(1)$ & $(2)$ & $(3)$ & $(4)$ \\
\hline 1 & $24-30$ & 18 & 31,03 \\
\hline 2 & $31-37$ & 16 & 27,58 \\
\hline 3 & $38-44$ & 15 & 25,87 \\
\hline 4 & $45-56$ & 9 & 15,52 \\
\hline \multicolumn{2}{|c|}{ Total } & 58 & 100.00 \\
\hline
\end{tabular}

\section{Karakteristik Berdasarkan Jenis Kelamin}

\begin{tabular}{|c|c|c|}
\hline No. & Jenis Kelamin & Frekuensi \\
\hline$(1)$ & $(2)$ & $(3)$ \\
\hline 1 & Laki-laki $(20-30)$ & 5 \\
\hline 2 & Laki-laki $(31-40)$ & 11 \\
\hline 3 & Laki-laki $(41-50)$ & 19 \\
\hline 4 & Laki-laki $>51$ & 2 \\
\hline 5 & Perempuan $(20-30)$ & 6 \\
\hline 6 & Perempuan $(31-40)$ & 3 \\
\hline 7 & Perempuan $(41-50)$ & 10 \\
\hline 8 & Perempuan $>51$ & 2 \\
\hline
\end{tabular}




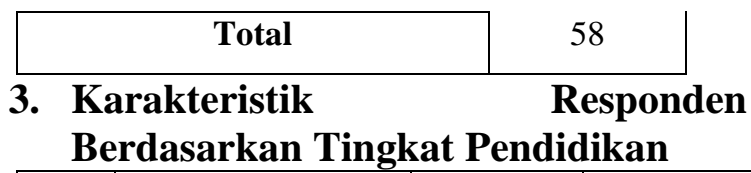

\begin{tabular}{|c|c|c|c|}
\hline No. & \multicolumn{1}{|c|}{ Pendidikan } & Frekuensi & $\begin{array}{c}\text { Prosentas } \\
\mathbf{i}(\boldsymbol{\%})\end{array}$ \\
\hline$(1)$ & $(2)$ & $(3)$ & $(4)$ \\
\hline 1 & SLTA & 12 & 20,69 \\
\hline 2 & Diploma III (Tiga) & 14 & 24,14 \\
\hline 3 & S1 & 28 & 48,28 \\
\hline 4 & S2 & 4 & 6,89 \\
\hline \multicolumn{2}{|c|}{ Total } & $\mathbf{5 8}$ & $\mathbf{1 0 0 . 0 0}$ \\
\hline
\end{tabular}

\subsubsection{Analisis Hasil Penelitian}

\section{Output Cronbach's Alpha}

\begin{tabular}{|c|l|c|}
\hline No. & \multicolumn{1}{|c|}{ Variabel Penelitian } & $\begin{array}{c}\text { Nilai } \\
\text { Cronbach's } \\
\text { Alpha }\end{array}$ \\
\hline$(1)$ & \multicolumn{1}{|c|}{$(2)$} & $(3)$ \\
\hline 1 & Kemampuan Kerja (X1) & $\mathbf{0 . 7 7 1}$ \\
\hline 2 & Motivasi Kerja (X2) & $\mathbf{0 . 7 6 5}$ \\
\hline 3 & Lingkungan Kerja (X3) & $\mathbf{0 . 7 7 1}$ \\
\hline 4 & Budaya Organisasi (X4) & $\mathbf{0 . 7 7 8}$ \\
\hline 5 & Kinerja Pegawai & $\mathbf{0 . 7 7 8}$ \\
\hline
\end{tabular}

\section{Pembahasan Hasil Penelitian}

1. Organisasi Berpengaruh Simultan Terhadap Kinerja Pegawai di Kantor Dinas Pendidikan Kabupaten Barito Selatan.

Berdasarkan hasil penelitian didapatkan angka $\mathrm{F}$ hitung sebesar 75,865 dengan Signifikansi $0,000<0,05$, artinya Kemampuan Kerja, Motivasi Kerja, Lingkungan Kerja dan Budaya Organisasi memiliki pengaruh simultan signifikan terhadap Kinerja pegawai di Kantor Dinas Pendidikan Kabupaten Barito Selatan. Temuan penelitian diperoleh nilai koefisien determinasi $\mathrm{R}^{2}$ (R Square) yaitu sebesar 0,851 menunjukkan bahwa Kemampuan Kerja, Motivasi Kerja, Lingkungan Kerja dan Budaya Organisasi mampu menjelaskan
Kinerja pegawai sekitar 85,10\%, sedangkan sisanya sebesar 14,90\% dijelaskan oleh variabel lain diluar penelitian ini. Variabel lain yang tidak tidak diteliti dalam penelitian ini misalnya, struktur organisasi, komitmen organisasi, kompensasi, kepuasan kerja dll.

\section{Motivasi Kerja Berpengaruh Signifikan} Terhadap Kinerja Pegawai.

Berdasarkan hasil analisis regresi linier berganda, menunjukkan bahwa terdapat pengaruh Motivasi Kerja terhadap Kinerja pegawai. Penelitian ini sesuai dengan penelitian yang dilakukan oleh Ra Armiaty, Zakhyadi Ariffi n (2014) pada Cabang Bank Kalsel yang berada di Wilayah Banjarmasin, bahwa Budaya Organisasi dan Motivasi berpengaruh simultan maupun parsial terhadap Kinerja Pegawai Frontliner. Hasil peneltian ini juga sependapat dengan Nimran (2007 : 32), bahwa pada dasarnya ada tiga karakteristik pokok dari motivasi yaitu : usaha, kemauan yang kuat dan arah tujuan. Ketiga karakteristik pokok motivasi ini dapat didefinisikan sebagai keadaan dimana usaha dan kemauan seseorang diarahkan kepada pencapaian hasil-hasil tertentu. Hasil-hasil yang dimaksud berupa produktivitas kehadiran atau perilaku kerja yang akan menuju kinerja yang lebih baik.

\section{Pengaruh Lingkungan Kerja} Terhadap Kinerja Pegawai

Berdasarkan hasil analisis regresi linier berganda, menunjukkan bahwa terdapat pengaruh Lingkungan Kerja terhadap kinerja pegawai. Hasil ini sesuai dengan hasil penelitian yang pernah dilakukan oleh Rodi Ahmad Ginanjar (2013). Lingkungan Kerja Terhadap Kinerja Karyawan Karyawan pada Dinas Pendidikan, Pemuda dan Olahraga Kabupaten Sleman. 
Penelitian ini bertujuan untuk mengetahui; (1) kondisi lingkungan kerja di Dinas Pendidikan, Pemuda dan Olahraga Kabupaten Sleman; (2) kinerja karyawan di Dinas Pendidikan, Pemuda dan Olahraga Kabupaten Sleman; dan (3) adakah pengaruh signifikan antara lingkungan kerja terhadap kinerja karyawan di Dinas Pendidikan, Pemuda dan Olahraga kabupaten Sleman.

\section{KESIMPULAN DAN SARAN}

Berdasarkan hasil penelitian dan pembahasan serta kesimpulan yang telah dijelaskan, peneliti memberikan saran-saran sebagai berikut di bawah ini :

1. Perlu dilakukan langkahlangkah yang dapat mempertahankan keadaan yang sudah sangat baik dan perlu meningkatkan Kinerja pegawai melalui Kemampuan kerja, Motivasi Kerja, Lingkungan Kerja dan Budaya Organisasi.

2. Mempertahankan atau bahkan meningkatkan dorongan yang lebih kuat terhadap variabel Lingkungan Kerja, karena hasil penelitian menunjukkan sebagai faktor yang dominan terhadap Kinerja pegawai di Kantor Dinas Pendidikan Kabupaten Barito Selatan.

3. Lebih aktif mempertahankan dan mengembangkan Lingkungan Kerja dan diperlukan :

a.

Pengel

olaan yang intens dan berkelanjutan.

b. Menetapkan sistem pengendalian yang jelas agar keadaan yang telah terbentuk dapat dipertahankan sepanjang waktu.

c. Menyesuaikan dengan perubahan lingkungan apabila lingkungan juga telah berubah.

\section{DAFTAR PUSTAKA}

Aswathappa K, 2002, Human Resource and Personnel Management Text and Cases, Third Edition, Tata McGraw-Hill Publishing Company Limited, New Delhi.

As’ ad, M., 1995, Psikologi Industri, Edisi Keempat, Jakarta, Penerbit Liberty.OK

Dessler, Gary. 2003. Manajemen Sumber Daya Manusia. Edisi Bahasa Indonesia, Jilid 2. Jakarta. PT. Prenhallindo

Fatah, Nanang, 2006, Landasan Manajemen Pendidikan, CV Rineka Cipta, Jakarta

Gardner, Howard, 1983. Frames of Mind: The Theory of Multiple Intelegences. New York: Basil.

Gibson, James L, dan Ivancevich, John M dan Donnely Jr, James H, 1996. Organisasi dan Manajemen. Terjemahan.. Jakarta : PT. Erlangga

Gujarati, D, 1995, Basic Economics, Mc Graw Hill International Book Company,Third Edition, Tokyo.

Gomes, Faustino, 2007, Manajemen Sumber Daya Manusia, Edisi 1, Andi Offset, Yogyakarta.

Ghozali, Imam. 2007. Aplikasi Analisis Multivariate dengan program SPSS. Semarang: Badan Penerbit Universitas Diponegoro.

Ghozali, Imam, 2001, Aplikasi Analisis Multivariate Dengan Program SPSS, Edisi II, Penerbit Badan Penerbit Universitas Diponegoro, Semarang.

Hasibuan, S. P, 2004, Manajemen Sumber Daya Manusia (Dasar dan Kunci

Keberhasilan), Penerbit Gunung Agung, Jakarta.

Heresy, Paul, dan Kenneth, H Blanchard, 1995. Manajemen perilaku Organisasi: 
Mendayagunakan Sumber Daya manusia. Edisi keempat, Terjemahan, Jakarta : Erlangga

Kolb, David A., 1984. Experiential Learning, Experience as the Source of Learning and Development. New York: Prentile-Hall, Inc.

Kontz, H, 2006, Manajemen, Edisi Kedelapan, Terjemahan Staf Editor, Penerbit Erlangga, Jakarta.

Lindawati, Tuty, 2001, "Budaya Organisasi Dalam Meningkatkan Kinerja", JURNAL WIDYA MANAJEMEN DAN AKUNTANSI, Universitas Katolik Widya Mandala Surabaya, Vol. 1 No. 3 Desember 2001.

Mangkunegara, 2005, Manajemen Sumber Daya Manusia Perusahaan, Penerbit PT. Remaja Rosdakarya, Bandung.

Mangkuprawira. Syafri, 2003, Manajemen Sumber Daya Manusia Stratejik,

Cetakan Kedua, Ghalia Indonesia, Jakarta

Mathis and Jackson, 2004, Human Resource Management, South-Western College Publishing.

Mitchell dan Larson, 2005, A Handbook Of Human Resources Management, Terjemahan, Elek Media Komputindo, Jakarta.

Moenir, 2002, Pengembangan Sumber Daya Manusia, Edisi Kedua, Cetakan Pertama, PT Rineka Cipta, Jakarta.

Mulyasa, 2004, Kurikulum Berbasis Kompetensi; Konsep, Karakteristik dan Implementasi, Cetakan Keempat, Remaja Rosdakarya: Bandung

Meyer, Allen,1993, A Three Component Conceptualization of Organizational Commitment, Human Resources
Management Review, Vol 1, No. 1, pp 61-89.

Nimran, Umar, 2007. Perilaku Organisasi. Surabaya : CV. Citra Media

Nitisemito, Alex S., 2004, Manajemen

Personalia, Cetakan 9, Edisi Ketiga, Penerbit Ghalia Indonesia, Jakarta.

Rina Armiaty, Zakhyadi Ariffi n, (2014). Judul : Pengaruh Budaya Organisasi dan Motivasi Terhadap Kinerja Pegawai Frontliner (Studi pada Cabang Bank Kalsel yang berada di Wilayah Banjarmasin) (Program Magister Manajemen Universitas Lambung Mangkurat Banjarmasin)

Rodi Ahmad Ginanjar (2013). Judul : Pengaruh Lingkungan Kerja Terhadap Kinerja Karyawan Karyawan pada Dinas Pendidikan, Pemuda dan Olahraga Kabupaten Sleman

Robbins, Stephen. P, 2001, Perilaku Organisasi : Konsep, Kontroversi, Aplikasi, Edisi kedelapan Terjemahan, PT. Prenhallindo, Jakarta.

Sambas (2008).Judul : Pengaruh Kompetensi Dan Iklim Kerja Terhadap Kinerja Staf di Unit Penunjang Medik Rumah Sakit Umum Pusat H. Adam Malik Medan Sekolah Pascasarjana Universitas Sumatera Utara Medan

Santoso, Singgih, 2002, Statistik Parametrik, Cetakan Pertama, Penerbit Elex Media Komputindo, Jakarta.

Siagian, Sondang P, 2003, Manajemen Sumber Daya Manusia, Edisi Pertama, PT Bumi Aksara, Jakarta.

Sedarmayanti, 2004, Sumber Daya Manusia dan Produktivitas Kerja, $\quad$ CV. Mandar Maju, Bandung.

Sugiyono, 2006, Metode Penelitian Bisnis, CV. Alfabeta, Bandung

Sujadi, 2007, Pengaruh Iklim Kerja dan Motivasi Kerja terhadap Kinerja Guru SMP 
Alumni Diklat PTBK di Bangkalan, Unpublished, Tesis Program Pascasarjana, Unesa Surabaya

Sharon, M., Kolb, 2003. Critical Social Skills for Adolescents With High Incidence Disabilities: Parental Perspectives. hhtp:/www.cec.sped.org.

Stoner, Raymond J., 2006, Human Resource Management, John Wiley and Sons, Singapore.
Ubaedy, AN, 2008. Berkarier di Era Global, Jakarta: PT. Elex Media Komputindo 